\title{
TECNOLOGIAS CARACOL E CULTURAS NA ERA \\ DA MOBILIDADE: COMUNICAÇÃO MÓVEL E IDENTIDADES NO TEMPO/ESPAÇO SHUAR
}

\author{
Saleta de Salvador Agra \& Yolanda Martínez Suárez
}

\begin{abstract}
Resumo
$\mathrm{Na}$ antologia móvel e na cosmovisão Shuar dinâmica, cíclica e unidimensional, o tempo transcorre e, com ele, simultaneamente, o espaço. Autores como Ling e Haddon enfatizaram a influência dos telemóveis nos modelos de deslocação e destacaram a "liberdade de contato" que nos oferecem, dada a sua natureza nómada, permitindo libertar-nos do contexto espacial e transladar-nos para o espaço de fluxos comunicativos, onde apenas se mantém o tempo, ou onde, como diria um Shuar, o espaço transcorre em simultâneo com o tempo. Se os aparelhos móveis nos instigam a uma vida nómada, convertendo-nos em caracóis (Fortunati, 2005) que carregam na carapaça toda uma rede de relações, uma análise aos usos dos telefones móveis - desse ponto de vista - e em relação a um povo de tradição nómada como os Shuar, revela-se extremamente pertinente. A metáfora do caracol, que gira em constante espiral e que os Shuar empregam para descrever a sua cosmovisão e o modo como concebem a natureza, recorda a atual tecnologia móvel que todos "carregamos em cima". O objetivo deste texto consiste, assim, em relacionar as cosmovisões da era móvel com a indígena Shuar, de forma a analisar as similitudes e diferenças na conceção espaciotemporal, assim como as suas repercussões identitárias.
\end{abstract}

\section{Palavras-chave}

Tempo; espaço; telefone móvel; Shuar; identidades

\section{INTRODUÇÃo}

A atual idade móvel, ou era móvel, marcada pela comunicação celular, convida-nos a repensar as categorias de espaço, tempo, proximidade e distância. Apela também à reflexão sobre a configuração e a transformação de identidades num mundo em mudança (de Salvador y Martínez, 2015b; Martínez, \& de Salvador, 2015; Martínez et al., 2015). Este texto debruça-se sobre estes dois grandes eixos: o espaço-tempo e as suas implicações nas identidades. A fim de percebermos a densidade do fenómeno, procuraremos repensar tais mudanças assumindo a tese de MacLuhan segundo a qual o meio é a mensagem. Também perspetivamos a problematização da tese de Wajcman (2008), autora que denuncia a falta de neutralidade da tecnologia, dado que esta remete para uma visão de mundo especial: a ocidental e masculina.

O texto versa sobre contextos espácio-temporais aparentemente situados à margem da globalização, incidindo, particularmente, na Amazónia equatorial - um "sul dentro do Sul" onde a realidade surge apresentada como "inacessível" e constituída de "conexões intermitentes" (Martinez \& Salvador, 2015b, Salvador \& Martinez, 2015a) que caraterizam a vida quotidiana das comunidades indígenas, como os Shuar. Tal 
permite-nos analisar as particularidades de um caso específico, contribuindo para tornar mais robusto o corpo teórico atual sobre a Idade Móvel (Mobile Age).

\section{Metodologia}

Para tentar responder a estas e outras perguntas, contamos com os resultados de um projeto de investigação intitulado "Ontologia móvel e tecno-cidadania indígena", na base do qual fizemos outras publicações (de Salvador y Martínez, 2015b; Martínez, \& de Salvador, 2015; Martínez et al., 2015).)'. Trata-se de uma pesquisa realizada com base num estudo de caso dos povos Shuar e Saraguro. O projeto foi financiado pela UTPL (Universidade Técnica Particular de Loja, Equador) em 2014 e desenvolvido sob coordenação de ambas as autoras do presente texto. A recolha de dados decorreu entre os meses de março e julho de 2014, no sul da província equatorial da Amazónia (Zamora Chinchipe), das áreas do Equador onde reside a comunidade indígena Shuar.

Tal como se encontra documentado (de Salvador y Martínez, 2015b; Martínez, \& de Salvador, 2015; Martínez et al., 2015), o estudo foi conduzido seguindo o processo da triangulação metodológica, através da combinação de técnicas quantitativas (um inquérito por questionário, anónimo e estruturado) e qualitativas (entrevistas semiestruturadas, observação participante e não participante). A amostra resultante do inquérito por questionário é composta por 135 indivíduos com idades compreendidas entre $12 \mathrm{e}$ 80 anos - 48,1\% são homens e 51,9\% são mulheres. Este inquérito permitiu recolher informação sobre os agregados familiares de pertença dos inquiridos, compostos, em média, por 3 a 6 elementos.

De forma a aprofundar algumas conclusões obtidas através do inquérito conduziram-se 22 entrevistas semiestruturadas junto dos membros Shuar. As idades dos entrevistados situam-se entre os 18 e os 55 anos, representativos de ambos os sexos. As entrevistas foram transcritas e analisadas segundo as regras de análise de conteúdo temática.

A observação participante foi realizada através dos grupos de discussão sobre tecnocidadania organizados nas comunidades Shaime, Tsarunts, Guayzimi, Zurmi, New Paradise, San Carlos de las Minas e Achunts. Incluímos ainda outras comunidades às quais tivemos acesso: Tiukcha, Zhacay, San Vicente de Caney, Yacuambi, Zamora, Zumbi, La Paz e Guadalupe, todas pertencentes à província de Zamora Chinchipe. Zamora é a província mais meridional das fronteiras do Equador com o Peru e é composta por nove cantões, sete dos quais (Zamora, Yantzaza, Centinela del Condor Paquisha, Yacuambi, The Pangui e Nangaritza) foram abrangidos neste estudo empírico.

O estudo envolveu a assinatura de um acordo com a Federação Provincial de Shuar Nacionalidade de Zamora Chinchipe (FEPNASH-ZCH) e um cronograma de reuniões com os dirigentes Shuar e com as suas próprias assembleias comunitárias. Tal permitiu-nos aceder às comunidades e realizar os grupos de discussão, o inquérito por questionário e as entrevistas, sempre num quadro de reciprocidade e respeito mútuos.

' Para ver informação sobre o projeto, consultar documentos disponíveis em http://smartland.utpl.edu.ec/sites/default/ files/ontologia_movil_o.pdf. 


\section{BREVES NOTAS SOBRE O POVO SHUAR}

Tal como temos frisado noutras publicações baseadas nesta pesquisa de Salvador y Martínez, 2015b; Martínez, \& de Salvador, 2015; Martínez et al., 2015) (mas torna-se relevante repetir no sentido da melhor compreensão do fenómeno), os Shuar constituem uma das mais célebres comunidades indígenas da Amazónia. Conhecidos como o povo das cascatas ou redutores de cabeças, os Shuar são uma comunidade que pertence à família jíbara. Shuar, que significa pessoa, é a auto-designação de povos heteronomeados como "Jivaros" de "xivar" conotados com atos de selvajaria. Atualmente, este povo é composto por 110.000 membros que vivem ao longo das fronteiras entre o Peru e o Equador (de Salvador y Martínez, 2015b).. No Equador residem nas sete províncias, sendo as mais numerosas as que se situam no extremo sul: Zamora Chinchipe e Morona Santiago. O último censo, datado de 2010, contava 79.709 Shuar, dos quais 5.474 viviam em Zamora Chinchipe, na província do Equador, onde esta pesquisa se desenvolveu mais intensivamente.

O povo Shuar é tradicionalmente seminómada (de Salvador y Martínez, 2015b). Move-se entre as terras de propriedade comunal da floresta amazónica onde se mantêm até que os solos se esgotem. As casas tradicionais são feitas de materiais perecíveis que protegem a família Shuar durante o período em que a terra é fértil. Povo de hábitos recolectores e caçadores/pescadores, respeitam a natureza e o habitat lhes dá para a alimentação. As festas tradicionais servem para agradecer a fertilidade da terra cíclica, consubstanciada na chonta, a palmeira que lhes dá abrigo, pois os pilares das casas são feitas desta madeira. A chonta é o fruto com o qual se faz a chicha, a bebida sagrada da comunidade Shuar, preparada pelas avós através de um processo trabalhoso e comunitário. Os Shuar são um povo com uma longa tradição de política marcada pela defesa dos costumes e territórios.

A globalização trouxe uma série de mudanças ao seu estilo de vida (de Salvador y Martínez, 2015b).Todavia, os Shuar têm mantido vivo o sentimento comunitário. A estrutura sociopolítica baseia-se na família patrilocal ${ }^{2}$, com ou sem laços de sangue. Um grupo de famílias funda uma comunidade e elege um representante político que as governa e representa fora da comunidade. O seu sistema político é de carácter democrático e muito participativo. Os síndicos, agrupados, por sua vez, em associações e federações provinciais e nacionais convocam assembleias com os vizinhos para decidir sobre assuntos públicos.

$\mathrm{Na}$ atualidade, já não conservam os seus trajes tradicionais e os seus artesanatos vão-se folclorizando. Apesar disso, têm consciência da importância de se socializar com o seu idioma, o shuar-Chicham, de base oral que se defende ante a influência crescente do castelhano nas suas comunidades.

Este povo, tradicionalmente guerreiro e muito zeloso do seu território, é hoje uma comunidade conectada com o mundo, física e virtualmente, se bem que de um modo "descontínuo" ou "intermitente", com várias brechas (Martinez, de Salvador \& de

\footnotetext{
${ }^{2}$ As sociedades patrilocais são aquelas nas quais a tradição dita que as famílias se formem na comunidade do marido, sendo que as mulheres são de fora da comunidade, vem para casar na terra do marido, deixando longe a sua aldeia e família de origem.
} 
Salvador, 2015). As comunidades Shuar, dado o progresso tecnológico e o avanço das vias de comunicação no espaço da amazónia do Equador, gozam de distintos níveis de acesso (de Salvador y Martínez, 2015b).

\section{TEMPo / ESPAÇo CÍCLICo NA ERA MÓVEL E NAS COSMOVISÕES SHUAR}

Segundo o teórico Lynch "o primeiro resultado relevante das telecomunicações prende-se com as alterações que provocam nas relações espaciotemporais entre indivíduos e, em consequência, na representação recíproca dos seus respetivos territórios" (Lynch, 2010, p. 78). Tais mudanças, fruto da chamada desterritorialização para a qual nos remetem as tecnologias digitais móveis, remete-nos para a existência de um intervalo espacial e temporal dinâmico que constitui o quotidiano. Seguindo as palavras de Duque, integrando as ideias de Thompson, as tecnologias, concretamente os telemóveis, projetam os sujeitos numa "simultaneidade desespacializada" (Duque, 2010, p. 49) e, por isso, se assume que os sujeitos, ao fazerem uso delas, partilham um espaço desterritorializado e, igualmente, um tempo comum.

As mudanças espaciotemporais provocadas pelas tecnologias são percebidas do seguinte modo, pelos nossos protagonistas3:

Agora, neste tempo, são mais os jovens, porque os mais velhos quase não, porque pouco interesse têm nisso, porque não deixam - assim o dizemos nós - os aparelhos, esses telemóveis e outros, não nos deixam trabalhar, fazem-nos deter neles. Então, deixam-nos... mudam-nos. As tecnologias mudam-nos, chama-nos mais ao telemóvel e não nos permitem nem o trabalho, nem o estudo. (Entrevistado 4, 40 anos)

Ah, olha, eu digo-te: a diferença é que, por exemplo, os teus avós sabiam a que hora amanhecia. Sabiam a que hora era meio dia através da observação da melodia do canto do galo. Pela manhã, sabiam a que horas estava a amanhecer, a que hora era madrugada, porque os pássaros começavam a chilrear e a rãs, igual. A que horas começa a entardecer, ou seja, sabiam tudo isso através dos sons. Ao invés, agora, nós não temos a agenda. É através do telemóvel que tu organizas e fixas um alarme. Tu dizes, por exemplo: - "agora mesmo o meu telefone vai tocar porque tenho de ir almoçar, porque tenho que sair com a minha filha!". Portanto, vê lá tu! Essa é a diferença: o toque do telemóvel do Shuar no mundo rural tem muitos sons. (Entrevistada 21, 43 anos)

Claro, com certeza que há mudanças. Antes era assim: fixávamos tal data, tínhamos de cumprir. Agora, por exemplo, há mudanças: planeei algo para

\footnotetext{
${ }^{3}$ A língua mãe dos Shuar é designa-se como shuar-chicham, idioma oral, cujas estruturas gramaticais e sintáticas distam do espanhol. Temos pretendido manter intactas as suas formas de expressão dado que as entrevistas se realizaram sempre em castelhano. O exercício de tradução para português poderá alterar algum elemento constituinte da língua.
} 
um domingo e nesse domingo acabou por acontecer algo mais urgente. Então, agora, falo rápido através do meu telemóvel e digo: "desculpe-me, mas tenho de sair por causa de outra coisa". Então, já aí vês as mudanças. Agora tudo é mais fácil, rápido. Então, seguindo estes caso, antes não saberia como avisar alguém e tinha de ir, ficava mal com ela ou ele, gerando desconfiança. (Entrevistado 1, 22 anos)

Tudo se converte num ciclo vicioso e a cada momento queres usar estes dispositivos e uma pessoa acaba zonza, ou, não sei, desviam-se coisas, mas, quanto a controlar o tempo ou o trabalho que cada um de nós tem, pode-se inclusivamente, organizar-se melhor, devido às aplicações que tens ali, para a tua agenda, o teu trabalho, as tuas reuniões, etc. É muito útil. Eu digo que é tudo uma única coisa e podes carregá-lo facilmente. (Entrevistado 11, 28 anos)

A circunstância dos telemóveis fez com que se pudessem organizar meIhor as coisas, pelo facto de se prolongar ... Geralmente nós também os usamos como despertadores ou como organizadores para o tempo. Temos já o tempo organizado. Acredito que isso é muito importante porque, às vezes, uma pessoa está distraída por aí e o telemóvel pode ajudar a saber o tempo. (Entrevistada 13, 45 anos)

(A tecnologia móvel) Influencia muito porque, às vezes, muda o tempo e, comparado ao tempo que seria na época dos nossos ancestrais era um pouco confuso (sic), porque agora a tecnologia, os telemóveis, pelo menos, às vezes não é tão necessário ter relógios e o tempo, às vezes, ajuda-nos através do telemóvel, da tecnologia, e isso pouco a pouco, vai mudando na nossa cultura. (Entrevistado 12, 35 anos)

Na cosmovisão Shuar dinâmica, cíclica e unidimensional o tempo transcorre e, com ele, simultaneamente, o espaço. Como indica um estudioso Shuar, a propósito da sua cultura "a conceção cíclica do espaço-tempo permitiu fazer girar a vida do homem Shuar numa mesma dimensão, distintamente do que acontece na conceção ocidental4" (Shakai, 2008, p. 32). Autores como Ling e Haddon (citado em Castells et al., 2006, p. 269) enfatizaram a influência dos telefones móveis e da micro coordenação nos modelos de deslocação e chamaram a atenção para a "liberdade de contato" que nos oferece esta nova tecnologia, dada a sua natureza nómada, permitindo aos sujeitos libertarem-se do contexto espacial físico e trasladarem-se para o espaço dos fluxos comunicativos, onde apenas o tempo se mantém. Ou, onde, como um Shuar evidenciaria, o espaço transcorre em simultâneo com o tempo (Tsawant), dimensão total do espaço-tempo, que "não tem tempos prefixados" (Shakai, 2008, p. 33). Unidimensionalidade, desterritorialização

\footnotetext{
${ }_{4}^{4}$ Para a profundar a conceção temporal do Ocidente, veja-se, por exemplo, Duque (2014).
} 
e nomadismo são, com as suas particularidades, os três traços principais da cosmovisão Shuar e da era móvel. Então, em que medida se vê reforçado o nomadismo Shuar com a apropriação da tecnologia móvel nestas comunidades indígenas? Que repercussões tem para o nomadismo Shuar a atual desterritorialização tecnológica? A apropriação da tecnologia móvel modifica a sua conceção espaciotemporal?

Perante uma conceção linear e progressiva, a cosmovisão Shuar recorre, sob a égide do termo Tsawant, a um pensamento dinâmico e cíclico (transcurso de um começo em que o fim é um novo começo) que se distancia de uma racionalidade evolucionista (retilínea, entre um começo e um fim), abraçando conceções cosmológicas orientais e, inclusivamente, remetendo para a conceção cíclica da antiga Grécia. A Tsawant, como tempo e espaço, categoria unitária que engloba indivisivelmente ambos os conceitos, tem a sua tradição em Kichwa com a palavra Pacha: o mundo. Estas duas culturas, coexistentes na Amazónia sul equatorial, partilham - entre outros traços - da visão unidimensional do espaço e do tempo.

No marco da cosmovisão andina, própria dos Kichwa, de Zamora-Chinchipe, estão presentes dois mundos: o da Allpamama-microcosmos - e a Pachamama - macrocosmos que comunicam entre si através de uma ponte. A Pachamama é a parte feminina criadora - junto com o Pachakamak, a parte masculina e dadora de vida. O Allpamama, ou mãe terra, é "dinâmica porque transforma a energia que fluí em círculos concêntricos" (Japón, s/f, p. 11). Esta conceção dualista -Allpamama/Pachamama- é partilhada pela cosmovisão Shuar, mais próxima de conceções como a platónica (mundo sensível/ mundo inteligível ou mundo das Ideias). A Terra é para os Shuar "uma ilha rodeada pelo céu" (Barriga, 1986, p. 63). O mundo da vida (Nunka) é um ensaio para o mundo autêntico - o mundo real ou divino (Nayaimp), ao qual se acede através de uma liana que se liga mediante o consumo de certas substâncias (como a Ayahuasca ou nantem). Substâncias estas que se tomam na companhia de um ancião sábio (o Wea).

As divindades Shuar (Arutam) estão na natureza - o habitat desta comunidade nómada que aproveita com gratidão um fragmento de selva amazónica. As jeas ou geas, casas tradicionais dos Shuar, representam, pela sua construção, a cosmovisão deste povo indígena. Assim, o teto simboliza o céu, as paredes são o horizonte que limita a terra. O piso do solo é a própria terra e, finalmente, no subsolo situa-se o mundo divino dos deuses e das almas (Barriga, 1986). As jeas são feitas de jonta5, o que as torna perecíveis. Tradicionalmente, duravam o tempo do próprio assentamento de uma família num certo lugar. Quer dizer, os anos que a terra da selva tardava em esgotar-se na caça, pesca e recoleção. Os hábitos de vida dos Shuar estão determinados pelo nomadismo, ou seminomadismo, se bem que, atualmente, como dissemos antes, os movimentos migratórios para as cidades por questões laborais ou estudos, a penetração da exploração mineira na selva equatoriana e a consequente diminuição das terras comunitárias tenham

\footnotetext{
${ }_{5}^{5}$ Uwi nijiamtamu ou festa da chonta e, juntamente com a festa da tsantsa (redução de cabeças) uma das principais celebrações tradicionais do povo Shuar. Na festa da chonta, os shuar dedicam cânticos à árvore da vida (chonta) cujos frutos são divinos. O ritual celebra a fertilidade da natureza que se renova com cada florescimento da chonta (cada doze meses), representando a unidade espaciotemporal equivalente ao ano. A não celebração da festa da chonta sugere morte (Barriga, 1986).
} 
transformado os hábitos seminómadas tradicionais desta comunidade, convertendo-os em nómadas contemporâneos. Além destas mudanças, cabe analisar a incidência da introdução dos dispositivos de comunicação móveis nas comunidades indígenas Shuar, nos hábitos de vida e, também, no seu próprio modelo de nomadismo.

Os shuar entrevistados falam das mudanças introduzidas pelos telefones móveis mostrando como os telemóveis reforçaram alguns dos seus traços típicos. Podemos observar que a perceção que têm os Shuar sobre as mudanças introduzidas pelas tecnologias móveis nos seus hábitos nómadas tradicionais estão relacionadas com o facto de os telemóveis acabarem por reduzir o seu nomadismo, nomeadamente o nomadismo que se deve à necessidade de comunicar entre si. Neste sentido também indicam que, no nomadismo tradicional, a deslocação a pé é modernizada devido ao uso dos telefones móveis que permitem que se possa fazer uma chamada para conseguir mais rapidamente um outro meio de locomoção, fazendo um percurso mais extenso de forma cómoda e mais rápida:

Bom, eu penso que mudou, no sentido em que, quiçá, antes o utilizamos por diversão, como the digo, por moda, para estarmos mais atualizados, mas hoje em dia, já o utilizamos como um meio em geral positivo para o trabalho, o estudo, para estar em contato com os nossos familiares a partir de lugares diferentes, distantes. Então, já não é necessário viajar e fazer tanta coisa. Então, o mais fácil. Eu penso assim: que na atualidade, no meu ponto de vista, agora, é com essa facilidade dada pela tecnologia que comunicamos entre nós, de modo mais fácil. (Entrevistado 1, 22 anos)

(O telemóvel) “(...) faz-nos poupar muitas viagens. Às vezes, podemos só fazer comunicações por telemóvel, uma chamada ou mensagem e não temos de perder mas tempo, a viajar para tal ou tal lugar. Nos poupamos (agora) viagens. (Entrevistada, 18 anos)

Agora somos, todo o mundo tem telefones para poder comunicar-se entre família, em caso de emergências, assim algo que acontece sem mais nem menos. Ao contrário, no caso de dirigirmos daqui a Pngui, é... longe. Se você vem de Pincho ou de Pangui, são muitos quilómetros para chegar aqui em casos de emergências e assim. Através do telemóvel pode-se chamar, digamos, ou dez ou quinze minutos antes e o carro chega aqui. (Entrevistado 9,26 anos)

A relação não monádica ou unitária é a essência da cosmovisão andina, à semeIhança do que acontece com o povo da amazónica Shuar, pois ambas defendem una série de traços distintivos, entre os quais se destaca: a relação e o espírito comunitário, assim como a conceção da natureza como um ser de conotações materiais e espirituais, num ciclo dinâmico espaciotemporal unidimensional. Como os Shuar, os Kichwa-Saraguro são nómadas. Uma marca dos seus trajes, o alforge para levar as suas mercearias 
de um lugar para outro, conta o seu passado de movimentos migratórios, desde a Bolívia (mitimaes) ao Peru (cusqueños). Segundo diversas teorias, de sua origem prévia o equatoriano, que não se encontra consenso. Quais caracóis que transportam na sua concha, o seu alforge, a sua casa e agora, o seu telemóvel.

Os dois povos presentes no território equatorial concebem do mesmo modo a totalidade espácio-temporal. Esta lógica, do fluxo de experiências contíguas, transmite-se de forma quase natural com a contemporânea Era Móvel (espaço fluxos-tempo), fazendo da metáfora do caracol, que transporta sua identidade às costas, um fiel reflexo desse dinamismo. Empregando as palavras de Shakai a respeito da sua cultura Shuar: "Assim, conseguem entender que a natureza não é estática mas que se move gerando dinâmica comparando-a com um caracol que gira de maneira espiral e aberta" (Shakai, 2008, p. 31).

O caracol é tomado como metáfora na dupla aceção: a espiral que gira sobre si mesma sem distanciar-se nunca do seu centro, num movimento unidimensional que mostra o dinamismo da natureza, a concha como portador de identidades que nos permite, qual alforge, acarretar as nossas senhas de identidade, o nosso lar, toda a nossa rede de relaciones, encerradas de este modo numa concha, contidas, agora, na carcaça metálica do dispositivo móvel: das tecnologias caracol.

\section{TECNOLOGIAS CARACOL: IDENTIDADES NÓMADAS}

Se os telefones móveis nos aproximam de uma vida nómada, convertendo-nos em caracóis (Fortunati, 2005) que carregamos na nossa carapaça toda a nossa rede de relações, como um variedade de possibilidade reais em cada instante, por obra e graça da hiperconectividade, uma análise das implicações da apropriação da telefonia móvel ${ }^{6}$ - desde esta perspetiva por parte de um povo de tradição nómada, como os Shuar, completada com a cosmovisão dos Kichwa-Saraguros da Amazónia equatorial, afigura-se especialmente interessante. Tal como afirma uma entrevistada:

Os telemóveis podes usá-los em qualquer lugar, podes levá-los nos teus bolsos e inclusivamente na tua bolsa, em contrapartida os filhos só os podes ter em casa, e pronto, assim podes comunicar-te com as pessoas que ficam em casa. (Entrevistada, 18 anos)

A citação reflete a mudança ontológica entre "estar ao telefone fixo" e "estar ao telefone móvel" que destacavam Plant (2001) e Ferraris (2005) nos princípios do século XXI. O "estar" transforma-se e com ele o "ser" emerge mostrando a mutação sobre nós mesmos. Da pergunta "quem és?", como resposta ao telefone fixo, passamos à questão “onde estás?" que dá por suposta a identidade (aparece o nome no ecrã). Com o telefone móvel, como se demonstra no uso da metáfora do caracol, a identidade, a casa, vai com os sujeitos: (os telemóveis) "tem a vantagem de o levarmos e poder receber as chamadas,

\footnotetext{
${ }^{6}$ Neste sentido, a apropriação dos Shuar estaria em correspondência com o que afirma Rosalía Winocur (2008) "Diferentemente de outras tecnologias, o uso do telefone móvel passou por um processo de reapropriação simbólica por parte dos vários grupos sociais (...), como os pobres, os indígenas, os imigrantes, os idosos e as crianças." (p. 186).
} 
onde formos" (Entrevistada 3, 18 anos). Quer dizer, o telemóvel surge como um elemento compósito da identidade e, assim, perdê-lo pode significar uma " grande ausência"

Houve um tempo em que sofria bastante por não ter um telemóvel próprio.

Isso foi a grande ausência e, desde que tive telemóvel, realmente mudei muito em relação à comunicação. Sem telemóvel não sinto-me nada. Assim, desaparecido. E, quando utilizo outro dispositivo emprestado às vezes a gente sente-se dono dessa máquina e tem sempre o receio de poder estragar ou causar algum dano na máquina, etc. Então, tratei de conseguir um bom telemóvel que me possa dar a melhor satisfação que preciso. (Entrevistado 11, 28 anos)

Os Shuar estão conscientes da importância atual da tecnologia móvel e da presença do povo shuar como cultura dentro deste "tempo moderno":

(O telemóvel) ajuda-nos também a manter a nossa identidade, nossa cultura, para que também seja parte dessa tecnologia, porque estamos a utilizar tecnologias avançadas. Não nos podem impedir de nenhum modo, porque, para nós, também é melhor. Praticar a cultura também é fazer parte da tecnologia que se vive no tempo moderno. (Entrevistado 12, 35 anos)

Os Shuar também têm presente que, no seu telemóvel, transportam a sua rede de relações. É uma crise se o perderem, pois, com ele, não só se extravia um dispositivo, mas toda uma série de contatos familiares e pessoais. Essa crise reforça a ideia de que o telefone móvel é identidade pessoal, a identidade "estendida" na atual Era Móvel. A ausência ou a perda do telefone móvel é interpretada por Stald (2008) como um desafio que supõe três implicações, a saber: i) a adaptação à rede social, ii) a própria posição social, isto é, fazer parte das atividades sociais e iii) a auto-perceção da identidade.

Ora vejamos: é caricato mas é que acabei de perder o telemóvel. Estava a viajar até Guayzimi e coloquei-o no bolso de trás das minhas calças. Cheguei lá, queria fazer uma chamada e vi que não estava com o telemóvel. Então, tudo ficou desastroso para mim, porque perdi os meus contatos. Não deu em nada. Foi frustrante porque tive de voltar para reaver os contatos. Inclusivamente perdi números, os contactos do meu pai em Quito. Então, como só tinha registado no telemóvel, e tudo isso, eu fui para trás para começar de novo. (Entrevistada 7, 29 anos)

Há muitos anos atrás, quando, ou seja, eu estava com ciúmes. Digamos que você tinha telefones celulares e eu não tinha. E sentia [ciúmes], quando eles tinham e eu não tinha como comunicar-me. (...) Sentia-me, assim, que eu não era nada! Que eu não era nada importante. Mas, depois que consegui comprar um telemóvel, e já, claro, tive os meus contatos, com amigos, com a juventude, com a minha infância. (Entrevistado 9, 26 anos) 
A falta de tempos prefixados deste povo nómada traduz a flexibilidade, uma característica elogiada pelos estudiosos das tecnologias digitais móveis. A metáfora do caracol - que gira em espiral constante e que os shuar usam, como explicitado, para descrever a sua cosmovisão e caraterização da natureza, faz lembrar a atual tecnologia móvel que todos carregados (transportamos em cima).

$\mathrm{Na}$ mitologia Shuar, o caracol -Kunku- representa a reciprocidade entre os dois pólos femininos - a constância (Kunku) e a prosperidade (Nunkui) - que, ao se fragmentarem-se, rompem o equilíbrio provocando a perda de prosperidade para o povo Shuar. Nunkui (a prosperidade, personificada e simbolizada na figura de uma menina) acaba-se quando a Kunku (a constância por mimar a Nunkui) a deixa só. Quando a humanidade se dá conta das consequências de tal perda, tenta reter a prosperidade (Nunkui), mas já nada pode conservar a não ser uma lembrança desta: as pedrazitas nantar que cada mulher Shuar deve ter para assegurar o bem-estar na sua casa. É assim que a metáfora do caracol, interpretada por dentro da cosmovisão Shuar, é especialmente interessante no contexto do estudo das mudanças trazidas pela era móvel: representa a base para a sobrevivência, através da produção de alimentos. Kunku (o caracol) e a condição de vida, reforçando, assim, a metáfora do caracol como identidade.

Os kichwa-Saraguro, que partilham com os Shuar, como já assinalámos, a zona de residência no sul da Amazónia equatorial, na província de Zamora Chinchipe, recorrem a outra forma de caracol, a concha (churu/churo), como símbolo de comunicação, de dinamismo. A concha é o meio tradicional de comunicação andina. Para além de uso musical, os indígenas kichwa-Saraguro usam-na para comunicar entre si e mandar mensagens às comunidades mais remotas.

Se admitirmos que somos tecnocaracóis com uma concha dura e rígida que é móvel, a sua forma espiral lembra-nos que nos podemos ir distanciando do centro (de nós) enquanto gira em torno de nós mesmos.

Esta lógica da espiral, sem começo nem fim orbita, assim, entre:

1. A portabilidade do telefone móvel permitir "de-distanciarmo-nos", segundo o jogo de palavra proposto por Kittler (2010), isto é, trazer à proximidade, ao nosso presente espácio-temporal, o longe/ distante. O próprio facto de a tecnologia ser portátil transporta-nos a lugares distantes sem perder as coordenadas espaço-temporais físicas, tal como tínhamos apontado na seção anterior.

2. A personalização (capas, coberturas, tons, etiquetas, fotografias, música, vídeos, etc.) dos próprios telefones nos remeter para nós mesmos, isto é, falam de nós por fora e por dentro. Usando as palavras de um representante político democrático Shuar, pertencente a uma das comunidades indígenas de Zamora-Chinchipe:

Bem no meu telemóvel, bem o que eu, às vezes, coloco fotos antigas (lejos), coloco fotos da minha esposa, dos meus filhos, às vezes, os meus companheiros perguntam-me às vezes, assim, às vezes: "tens algumas fotos da tua paróquia?" Digo-lhe que as tenho (no telemóvel). (Entrevistado 6, 38 anos)

A portabilidade e a personalização são duas das características que, perspetivadas a partir do seu contexto remoto, de acesso limitado e cobertura intermitente, confirmam que "a incorporação do telefone móvel na vida diária do ser humano não só altera as 
dimensões do tempo e do espaço, como também modifica a sua perceção e maneira de relacionar-se com o ecossistema (Fidalgo et al., 2013, p. 545). Nesse sentido, transforma as identidades.

\section{CONSIDERAÇõES FINAIS}

Tal como havíamos assinalado noutros trabalhos (de Salvador y Martínez, 2015b; Martínez, \& de Salvador, 2015; Martínez et al., 2015), a apropriação dos telefones móveis por parte das comunidades Shuar desencadeia uma série de particularidades no que respeita à conceção espaciotemporal, assim como aos processos de configuração identitária deste povo.

A unidimensionalidade própria da cultura Shuar, que concebe o tempo-espaço como um só elemento, parecera confluir com o espaço dos fluxos comunicativos móveis e com o tempo intemporal (Castells et al., 2006). Contudo, posto que a apropriação das tecnologias móveis se dá desde que a cultura Shuar começou a ser influenciada pela cosmovisão ocidental (por exemplo, os hábitos de trabalho e de estudo mudaram) a apropriação tecnológica representa certas alterações na comunhão-com a natureza - a base do dinamismo Shuar. Como indica um dos entrevistados Shuar, os alarmes dos celulares estão a substituir os sons da natureza como indicações espácio-temporais para os membros das comunidades.

De outro lado da metáfora do caracol - o da identidade - observa-se como o nomadismo desta nacionalidade indígena, que, em teoria, parecia relacionar-se de forma natural com a cosmovisão da Era Móvel, se vê reduzido agora, quando a sua causa é comunicativa, já que se substituem os pés pelas rodas dos veículos. Chamamos através dos telemóveis para que nos ajudem. De novo, a situação de aculturação presente nestas comunidades indígenas pode representar uma explicação sobre a separação entre os sistemas ou ideologias Shuar e a tecnologia móvel quando, em princípio, e a nível teórico, se apresentavam de forma uniforme (semelhante).

A apropriação tecnológica dos telemóveis pelos povos da selva amazónica equatorial implica uma série de repercussões identitárias, não só porque as tecnologias transportam uma carga ideológica (Wacjman, 2008), mas também porque o contexto de apropriação é um contexto já influenciado pelas culturas ocidentais. Os Shuar que estudámos estavam a perder a sua cosmovisão, muito antes da chegada dos telefones móveis e já se apropriaram dos telemóveis a partir de uma base constituída por uma cultura estrangeira. Como nas sociedades "modernas" (Stald, 2008), nas sociedades amazónicas, o telefone móvel representa um apêndice da identidade. Perdê-lo implica uma "grande ausência" e esta gera uma série de consequências negativas para os sujeitos, que sentem a necessidade de recuperar e conservar o seu tecnocaracol.

\section{REFERÊNCIAS}

Barriga, F. (1986). Etnografía ecuatoriana II. Shuaras. Quito: Instituto Ecuatoriano de Crédito Educativo y Becas (IECE). 
Castells, M., Fernandez, M.; Lichuan, j. \& Sey, A. (2006). Comunicación móvil y sociedad: una perspectiva global. Barcelona: Ariel.

De Salvador Agra, S. \& Martínez Suárez, Y. (2015a). Apropiaciones comunitarias del telefone móvil en los indígenas shuar. Revista Internacional de Comunicación y Desarrollo, 1, 41- 49, Acedido em http://www. usc.es/revistas/index.php/ricd/article/view/2178/2461.

De Salvador Agra, S. \& Martínez Suárez, Y. (2015b). Nomadism and Intermittent Ubiquity in 'Off the Grid' Shuar People. Communication Q Society, 28 (4), 87-105. Acedido em http://www.unav.es/fcom/ communication-society/es/resumen.php?art_id=549.

Duque, E. (2014). É possível sair do presente? Uma teoria prospetiva. In E. Araújo; E. Duque; M. Franch \& J. Durán (Eds.), Tempos Sociais e o Mundo Contemporâneo - As Crises, as Fases e as Ruturas (pp.154- 169). Braga: Centro de Estudos de Comunicação e Sociedade, Universidade do Minho.

Duque, F. (2010). Ontología negativa. Móviles sin sustancia, distancia sin sitios. In G. Aranzueque (Ed.), Ontología de la Distancia. Filosofías de la Comunicación en la Era Telemática (pp. 23-55). Madrid: ABADA Editores.

Aranzueque, G. (2010). Ontología de la distancia. Filosofías de la comunicación en la era telemática. Madrid: ABADA Editores.

Ferraris, M. (2005). Dove sei? Ontologia del telefonino. Milano: Bompiani.

Fidalgo, A.; Telleria, A.; Carvalheiro, J.R.; Canavilhas, J. \& Correia, J. (2013). El ser humano como portal de comunicación: La construcción del perfil en el telefone móvil. Revista Latina de Comunicación Social, 68. Acedido em http://www.revistalatinacs.org/o68/paper/989_Corvilha/23_Telleria.html.

Fortunati, I. (2005). Mobile phone and the presentation of self. In R. Ling \& E. Pedersen (Eds.), Mobile Communication and the Re-Negotiation of the Social Sphere (pp. 203-18). Londres: Springer.

Japón Gualán, R. (s/f). La cosmovisión andina. In M. A. Martin López (Coord.), Los Saraguros. Cosmovisión, Salud e Identidad Andina: Una Mirada desde sí Mismos (pp. 9-38). Espanha: Diputación de Córdoba

Kittler, F. (2010). El Des-alejar. In G. Aranzueque (Ed.), Ontología de la Distancia. Filosofías de la Comunicación en la Era Telemática (pp. 9-21). Madrid: ABADA Editores.

Lynch, E. (2010). La felicidad de la nómadas. In G. Aranzueque (Ed.), Ontología de la Distancia. Filosofías de la Comunicación en la Era Telemática (pp. 75-99). Madrid: ABADA Editores.

Martínez Suárez, Y. \& de Salvador Agra, S. (2015). Objetos nómadas digitales: caso de estudio las comunidades shuar ecuatorianas. Comunicaçao, Midia e Consumo, 12(33), 73-91. Acedido em http:// revistacmc.espm.br/index.php/revistacmc/article/view/889.

Martínez Suárez, Y.; de Salvador, Agra, S. \& de Salvador, González, X. (2015). Triplemente marcadas: desconexiones comunicativas en la Amazonía sur ecuatoriana. Cuadernos.info. Comunicación y medios en Iberoamérica, 36, 89-107. doi: 10.7764/cdi.36.716 Acedido em http://www.cuadernos.info/index.php/ CDI/article/view/716/pdf.

Plant, S. (2001). On the mobile. The effects of mobile telephones on social and individual life. Acedido em http:// www.momentarium.org/experiments/7a1ome/sadie_plant.pdf.

Shakai, M. (2008). Las costumbres, ritos y creencias de la cultura shuar como generadoras de las manifestaciones de reciprocidad y comunitareidad en la zona de Chiguaza. Dissertação de Mestrado, Universidade de Cuenca, Cuenca, Equador. 
Stald, G. (2008). Mobile identity: Youth, identity, and mobile communication media. In D. Buckingham (Ed.), Youth, identity, and digital media (pp. 143-164). Cambridge: The MIT Press.

Wajcman, J. (2008). Tecnofeminismo. Madrid: Cátedra.

Winocur, R. (2008). El móvil, artefacto ritual para exorcizar la otredad. In M. B. Albornoz \& M. Cervino (Comp.), Comunicación, Cultura y Política. Quito: Flacso 50 años.

Traduzido do espanhol por Ana Moreira

\section{FinANCIAMENTO}

Este trabalho apresenta os principais resultados de uma investigação financiada pela Convocatória de Fundos Internos de Investigação da Universidade Técnica Particular de Loja, 2014.

\section{NOTAS BIOGRÁFICAS}

Saleta de Salvador Agra é doutorada em Filosofia e doutorada en Semiótica e mestre em Género e Politicas Públicas. É membro do Instituto de Comunicação, Universidade Autónoma de Barcelona (InCom-UAB) e investigadora associada da Cátedra UNESCO de Cultura e Educacão para a Paz, UTPL- Equador. É atualmente professora na Universidade de Vigo, Espanha.

E-mail: saletadesalvador@gmail.com

Universidade de Vigo, Facultade CC. da Educación, Campus das Lagoas, Ourense,Espanha

Yolanda Martínez Suárez é doutorada em Filosofía e membro Instituto de Comunicação, Universidade Autónoma de Barcelona (InCom-UAB) e investigadora associada da Cátedra UNESCO de Cultura e Educacão para a Paz, UTPL- Equador.

E-mail: dalanyom@gmail.com

Instituto de Comunicação, Universidade Autónoma de Barcelona (InCom-UAB), Campus UAB - Edifici N, planta 1, E-08193 Bellaterra (Cerdanyola del Vallès), Barcelona, Espanha

\section{* Submetido: : 18-06-2015}

* Aceite: 21-07-2015 